\title{
Determining the Minimum Inhibitory Concentration of Medium Chain Fatty Acids for generic Escherichia coli, Enterotoxigenic Escherichia coli, Salmonella Typhimurium, Campylobacter coli, and Clostridium perfringens.
}

Roger A. Cochrane

Kansas State University

Raghavendra G. Amachawadi

Kansas State University

Sarah E. Remfry

Kansas State University

Annie B. Lerner

Kansas State University

Tiruvoor G. Nagaraja

Kansas State University

Jason C. Woodworth

Kansas State University

Steve S. Dritz

Kansas State University

Michael D. Tokach

Kansas State University

Cassandra Jones ( $\sim$ jonesc@ksu.edu )

Kansas State University https://orcid.org/0000-0002-0671-8879

Research article

Keywords: Enterotoxigenic Escherichia coli (ETEC), Enterotoxigenic, Enterotoxigenic

Posted Date: July 17th, 2020

DOI: https://doi.org/10.21203/rs.3.rs-41380/v1

License: (c) (i) This work is licensed under a Creative Commons Attribution 4.0 International License.

Read Full License 


\section{Abstract}

Research has demonstrated that medium chain fatty acids (MCFA) can serve as reduction strategies for bacterial and viral pathogens in animal feed and ingredients. However, it is unknown how the type or level of MCFA impact bacteria growth. This can be tested through a minimum inhibitory concentration (MIC) benchtop assay, which identifies the lowest concentration of a chemical that prevents visible growth of a bacterium. The objective of this study was to 1) determine the MCFA MIC of C6:0, C8:0, C10:0, and C12:0 for generic Escherichia coli, Enterotoxigenic Escherichia coli, Salmonella Typhimurium, Campylobacter coli, and Clostridium perfringens; 2) determine the MIC of commercial based MCFA products against the same bacteria; and 3) determine the effect of 2 commercial based MCFA products on the quantification of Enterotoxigenic Escherichia coli. For Exp. 1 and 2, MIC were determined by modified microbroth dilution method using a 96 well microtiter plate with a concentration of $105 \mathrm{CFU} / \mathrm{mL}$ for each bacterial strain. For Exp. 3, the two products selected for quantification were mixed with a complete swine diet and inoculated with two concentrations (106 or 102 $\mathrm{CFU} / \mathrm{g}$ of feed) of a Nal${ }^{R}$ strain of Enterotoxigenic Escherichia coli (ETEC) for bacterial enumeration. From Exp. 1, the MIC of MCFA varied among bacteria species. The lowest MIC of the MCFA was $0.43 \%$ of a 1:1:1 blend of C6:0, C8:0, and C10:0 for Campylobacter coli, 0.25\% C12:0 for Clostridium perfringens, 0.60\% 1:1:1 blend for generic Escherichia coli, 0.53\% C6:0 for ETEC, and 0.40\% C6:0 for Salmonella Typhimurium. In Exp. 2, products containing high concentrations of C6:0 or C8:0 had lower MIC in gram negative bacteria. In Exp. 3, feed containing either of the commercial based MCFA products reduced (linear, $P<0.05$ ) quantifiable ETEC. Overall, the inhibitory efficacy of MCFA varies among bacteria species. This suggests that MCFA mixtures may provide a wider spectrum of bacterial control. As commercial products containing MCFA become available for livestock, it is important to consider the interaction between MCFA chain length and concentration on the potential to effectively mitigate various feed-based bacteria.

\section{Introduction}

Medium chain fatty acids (MCFA) have been demonstrated to significantly reduce problematic bacterial and viral contamination in animals, animal feed and feed ingredients. ${ }^{1-7}$ Compared to other feed additives, MCFA are unique in their potential mode of action. It is thought that the MCFA carry bacteriostatic and bactericidal properties by causing a destabilization of the bacterial double phospholipid bilayer membrane and causing the leakage of intracellular content. ${ }^{2}$ It is also thought that the MCFA can acidify the cell by liberating $\mathrm{H}^{+}$ions, leading to cell death. ${ }^{2}$ More recently, a $2 \%$ inclusion of a 1:1:1 ratio of $\mathrm{C6}: 0, \mathrm{C8}: 0$, and C10:0 reduced Salmonella enterica subsp. enterica serovar Typhimurium from 2.35 to $0.66 \log$ CFU/g within 1 day. ${ }^{3}$ The MCFA were also very effective on the initial inoculation day compared to the inoculated feed matrices containing no mitigation additives ( 2.35 vs. $5.45 \mathrm{Log}$ $\mathrm{CFU} / \mathrm{g}$ respectively). ${ }^{3}$ However, there is a lack of information regarding which specific MCFA is the most effective, whether combinations of different MCFA exhibit additive effects, and what the optimal level of MCFA is that will impact various bacteria associated with animal production. This can be determined 
utilizing a minimum inhibitory concentration (MIC) benchtop assay, which identifies the lowest concentration of a treatment that prevents visible growth of a bacterium. Therefore, the objective of this study was to determine the minimum inhibitory concentration of specific MCFA and commercial products for Campylobacter coli, Clostridium perfringens, generic Escherichia coli, Enterotoxigenic Escherichia coli, and Salmonella Typhimurium as well as their potential application in feed as a reduction strategy.

\section{Materials And Methods}

\section{Bacterial inoculum}

Bacterial strains of generic Escherichia coli (E. coli) ATCC 25922, Enterotoxigenic Escherichia coli (ETEC) 3030-2, and Salmonella enterica serotype Typhimurium (S. Typhimurium) ATCC 14028 were grown using Luria Bertani, Campylobacter coli (C. coli) 7A \#2016-1 using Mueller-Hinton, and Clostridium perfringens (C. perfringens) 4026 using anaerobic Brain Heart Infusion broth medium at $37^{\circ} \mathrm{C}$ for $24 \mathrm{~h}$. For $E$. coli, ETEC, $S$. Typhimurium, and $C$. coli, $1 \mathrm{ml}$ of bacterial inoculum was serially diluted using $9 \mathrm{ml}$ of PBS to achieve one concentrations $\left(10^{5} \mathrm{CFU} / \mathrm{ml}\right)$ for each bacterial strain. For Clostridium perfringens, the bacterial concentration was adjusted to $0.5 \mathrm{McF}$ arland Standards using fresh Brain Heart Infusion broth medium per Clinical and Laboratory Standards Institute recommendations. ${ }^{8}$

\section{Experiment 1 MIC Determination of MCFA}

For $E$. coli, ETEC, $S$. Typhimurium, and $C$. coli the compounds tested were $C 6: 0^{\mathrm{a}}, \mathrm{C8}: 0^{\mathrm{a}}, \mathrm{C} 10: 0^{\mathrm{a}}$, and a 1:1:1

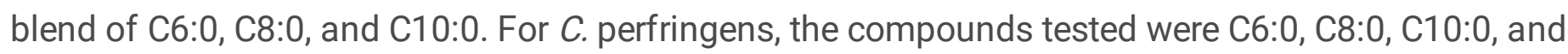
$\mathrm{C} 12: 0^{\mathrm{a}}$.

The MIC were determined by the micro-broth dilution method as per Clinical Laboratory Standards Institute CLSI guidelines ${ }^{8}$ in $E$. coli, ETEC, S. Typhimurium, and $C$. coli from $0.1 \%$ until an MIC was established, with a maximum tested level of $1.0 \%$. The MIC was also determined using the same method for $C$. perfringens, with a maximum tested level of $2.0 \%$. There were three replications per product and bacteria combination.

\section{Experiment 2 MCFA Profiles and MIC Determination of Commercially-Based Products}

The fatty acid profile of 21 commercially-based products was analyzed, with an emphasis on the MCFA concentration. The 24 products were, 1.) Product $A^{b}$, 2.) Product $B^{c} 3$.) Product $C^{b}$, 4.) Product $D^{d}, 5$.) Product $E^{d}$, 6.) Product $F^{d}$, 7.) Product $G^{d}$, 8.) Product $H^{e}$ 9.) Product $I^{f}$, 10.) Product J ${ }^{f}$, 11.) Product $K^{g}$, 12.) Product $L^{h}$, 13.) Product $M^{h}$, 14.) Product $N^{f}, 15$.) Product $O^{f}, 16$.) Product $P^{f}, 17$.) Product $Q^{f}, 18$.) Product $R^{f}$, 19.) Coconut Oil ${ }^{9}$, 20.) Palm Oil ${ }^{g}$, and 21.) Palm Kernel Oilg. Samples were analyzed according to procedures outlined by Sukhija and Palmquist ${ }^{9}$. From this analysis, Product $A, B, G, H$, and a commodity fat source (coconut oil) were selected as having representative MCFA profiles for use in MIC assays. The profiles were selected based on products having the highest concentrations of $\mathrm{C6:0}$ and C8:0 
within the fatty acid profile and coconut oil because of its natural source of MCFA and medium chain triglycerides. The MIC were determined as described in Exp. 1 in E. coli, ETEC, S. Typhimurium, and $C$. coli from $0.1 \%$ until an MIC was established, with a maximum tested level of $5.0 \%$. There were three replications per product and bacteria combination.

\section{Experiment 3 Quantification of Enterotoxigenic Escherichia coli-inoculated feed after treatment with two commercially-based MCFA-containing products}

Based on their lower MIC compared to other products tested in Exp. 2, Products A and B were selected as treatments to determine their reduction capacity in swine feed inoculated with ETEC. The strain of ETEC was first made resistant to $50 \mu \mathrm{l} / \mathrm{ml}$ nalidixic acid $\left(\mathrm{Nal} /{ }^{R}\right)$ antibiotic before being used for inoculation. A complete swine diet was either left un-inoculated and untreated, or mixed with $0.00,0.25,0.50,1.00$, or $2.00 \%$ Product A or B and inoculated with ETEC. For inoculation, $1 \mathrm{~g}$ of each feed sample was mixed with $1 \mathrm{ml}$ of $\mathrm{Nal}{ }^{R} E T E C$ at one of two concentrations $\left(10^{6}\right.$ or $10^{2} \mathrm{CFU}$ per $\mathrm{g}$ of feed) of bacteria. The higher concentration was utilized for quantification of ETEC and the lower for detection. The 10 treatments were: 1.) control feed with no bacteria; 2 ). Control feed inoculated with bacteria and no addition of an additive; 3.) $0.25 \%$ Product $A$; 4 .) $0.5 \%$, Product $A$; 5.) $1.0 \%$, Product $A ; 6$ ). $2 \%$. Product $A$; 7.) $0.5 \%$ Product $B$; 8.) 1.0\% Product B; 9.) 2.0\% Product B; and 10.) $4.0 \%$ Product B. The levels for each product were selected based on the results of Exp. 2. Product $A$ was tested at a lower inclusion level in the feed because of the lower MIC value established in Exp. 2. Product B was then tested at higher inclusion levels because of the higher MIC value that was established in Exp. 2. It was also determined that treatment 1 was confirmed to be negative of ETEC and was not included in the statistical model.

Samples were incubated at $37^{\circ} \mathrm{C}$ for $24 \mathrm{~h}$. Then, $1 \mathrm{~g}$ of the incubated feed containing bacterial inoculum was suspended in $9 \mathrm{ml}$ of PBS, serially diluted, and plated onto MacConkey agar containing nalidixic acid. The plates were incubated at $37^{\circ} \mathrm{C}$ for $24 \mathrm{~h}$ for bacterial enumeration using a standard plate count for viable cells. There were three replications per product and bacteria combination.

\section{Statistical Analysis}

Data from each MIC experiment were analyzed as a completely randomized design using PROC GLIMMIX in SAS ${ }^{i}$ to evaluate the effect of each treatment within each bacterium. If the MIC value was greater than the detection limit of the analysis, the next logical inclusion level (increase in $0.1 \%$ inclusion) was utilized for the statistical analysis. For Exp. 3, the PROC GLIMMIX procedure of SAS ${ }^{i}$ was utilized to evaluate linear and quadratic contrasts of increasing product levels. The coefficients for the unequally spaced linear and quadratic contrasts utilized in Exp. 3 were derived using the PROC IML procedure in SAS ${ }^{i}$. In all experiments, results for treatment criteria were considered significant at $P \leq 0.05$.

\section{Results}

\section{Experiment 1}


The MIC of each MCFA in $C$. coli, $C$. perfringens, $E$. coli, ETEC, and $S$. Typhimurium, are presented in Table

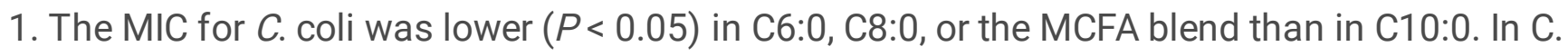

perfringens, the longer chain fatty acids were more effective with $\mathrm{C} 12: 0$ and $\mathrm{C} 10: 0$ providing the lowest $(P$ $<0.05)$ MIC results with $\mathrm{C} 12$ being the most effective $(P<0.05)$ overall. Within generic $\mathrm{E}$. coli, the 1:1:1 MCFA blend of $\mathrm{C} 6: 0, \mathrm{C} 8: 0$, and C10:0 provided the lowest $(P<0.05)$ MIC value followed by $\mathrm{C} 6: 0$ and C8:0 Within Enterotoxigenic E. coli, C6:0 had a lower $(P<0.05)$ MIC than C8:0, which was still lower $(P<0.05)$ than either C10:0 or the MCFA blend, which were greater than the maximum tested value of $1 \%$. In Salmonella Typhimurium, C6:0 resulted in an MIC similar $(P>0.05)$ to C8:0. However, C6 did differ $(P<$ $0.05)$ from the blend. Again, no MIC was determined for C10:0 within $S$. Typhimurium.

\section{Experiment 2}

The fatty acid profile varied widely in the 21 commercially-based products (Table 2).

Based on these analysis, Product A, B, F, G, and coconut oil were selected as candidate products for MIC determination in gram negative bacteria due to their high concentrations of $\mathrm{C6:0} 0$ and $\mathrm{C8:0}$. In $C$. coli, the MIC for Product B was lower $(P<0.05)$ than either Product F or G, with Product A being intermediate (Table 3). Product A and B had lower $(P<0.05)$ MIC in generic E. coli, ETEC, and Salmonella Typhimurium than other tested products. The MIC for coconut oil was not detected in any bacteria as it was greater than the maximum tested level of $5.0 \%$.

\section{Experiment 3}

Due to their efficacy in the MIC determination, Product A and B were selected as treatments to determine their effect on detectable or quantifiable ETEC in feed. In the higher concentration of bacteria, Product A resulted in a linear decrease (linear, $P<0.05$ ) in the number of quantifiable bacteria (Table 4). For Product $\mathrm{B}$, as the inclusion level increased, the number of quantifiable bacteria quadratically decreased $(P<0.05)$. In the lower concentration of bacteria, Product A again resulted in a linear decrease (linear, $P<0.05$ ) in the number of quantifiable bacteria (Table 5). However, in Product $B$ no linear or quadratic response was observed $(P>0.10)$.

\section{Discussion}

Our research supports previous findings where the MIC varies among MCFA and bacteria combinations. ${ }^{10,11}$ For example, Skrivanova et al. showed an inclusion of C8:0 in two stains of $C$. perfringens (CCM 4435 and CNCTC 5459) resulted in MICs of $0.2 \%$ and $0.1 \%$ respectively. ${ }^{12}$ However, when tested in E. coli CCM 3954 and 4225, the MIC of C8:0 and C10:0 were the same between the two bacterial strains within the same MCFA. ${ }^{12}$ Meanwhile, the MIC in C6:0 was greater than the tested maximum inclusion of $0.5 \%$ for $E$. coli, $S$. typhimurium,Salmonella enteritidis, and $C$. perfringens. ${ }^{12}$ This is in general agreement with our research. However, our findings extended the range of MIC detection, which allowed for the first time to the authors knowledge for the MIC values of different MCFA to be established for $E$. coli and $C$. perfringens. 
Notably, the most effective MCFA was different when evaluating gram negative (E. coli, ETEC, $S$. Typhimurium, $C$. coli) compared to gram positive bacteria ( $C$. perfringens). The membrane likely impacts the inhibitory process, as gram positive bacteria have thicker and more rigid peptidoglycan layers that provide increased protection for the phospholipid bilayer. ${ }^{14}$ Furthermore, gram positive bacteria do not have the outer cell membrane like gram-negative bacteria do, so the mode of action of interfering with the cellular membrane may be different.

Based on the results from Exp. 1, we had hypothesized that feed additives rich in C6:0 would have greater efficacy than those rich in C10:0 or C12:0. This was confirmed, as the inclusion of C6:0 in E. coli, ETEC, and $S$. Typhimurium provided the lowest MIC values. Notably, there was also an apparent synergistic effect of including a blend of MCFA in E. coli, $S$. Typhimurium, and $C$. coli. In $C$. coli, the combination of the MCFA blend provided inhibitory benefit and could be the reason why Product $B, F$, and $G$ presented an MIC value of approximately $20 \%$ less than in the other bacteria tested. Products A, B, F, and G could contain other compounds within the product profile and were only selected based on the amount of MCFA within their profile. The other compounds that make up these products could also lead to the inhibitory effects that were observed. Also of note is that no MIC value was obtained for coconut oil. This could be because the MCFA in coconut oil are largely bound as triglycerides, which are not thought to interact with the cell membrane of gram negative bacteria without cleavage by lipase.

Results in Exp. 3 were based on the inclusion of each treatment into a complete swine diet and inoculated with two concentrations of ETEC. The higher concentration was utilized to capture the quantification of reduction associated with each treatment against the bacteria. The lower concentration was used as detection for the ETEC against each treatment. It should also be noted that Exp. 3 was a quantification not an MIC experiment. Results were similar to expectations as linear decreases of 0.62 and $0.54 \mathrm{log}$ $\mathrm{CFU} / \mathrm{g}$ of feed were noted for Product $\mathrm{A}$ in both the higher and lower bacteria concertation, respectively. However, this was not the case in Product B as no linear or quadratic decrease was noted at the lower concentration of ETEC tested.

This research extended previous knowledge to establish an MIC for four MCFA in five different bacteria. The effect of feeds or ingredients on MIC is still unknown, and necessary to consider as one applies this knowledge. Quantification was carried out in a complete feed matrix to determine the reduction each treatment provided against ETEC. However, further research is warranted to develop a complete feed MIC assay beyond quantifying bacteria to determine how a culture-based MIC method can be translated to a feed-based model.

In summary, the efficacy of MCFA varies among bacteria species. As commercial products containing MCFA become available for livestock feed manufacturers, it is important to consider the interaction between MCFA type and concentration on the potential for products to effectively mitigate various feedbased bacteria. It appears that $\mathrm{C} 6: 0$ and $\mathrm{C} 8: 0$ are more effective mitigants than $\mathrm{C} 10: 0$ in gram negative bacteria, while $\mathrm{C} 12: 0$ was the most effective in the gram-positive $C$. perfringens. 


\section{Declarations}

Ethics approval and consent to participate: No animals or humans were used in this research. The Kansas State University Institutional Biosafety Committee approved the use of biosafety-level pathogens for this project via \#986.

Consent for publication: There were no human or animal participants that were part of this research. Therefore, no consent for publication is necessary.

Availability of data and material: The datasets used and/or analyzed during the current study available from the corresponding author on reasonable request.

Competing interests: The authors declare no financial/non-financial competing interests.

Funding: National Pork Board (award \#17-049).

Authors' Contributions: RAC conducted the study and wrote the initial draft, RGA, SER, and TGN supervised the study and ensured validation of controls, $A B L$ assisted with data collection and interpretation, JCW, SSD, MDT, and CKJ obtained funding for the project, reviewed data results and assisted in interpretation, and complete edits. All authors of the manuscript have read and agreed to its content and are accountable for all aspects of the accuracy and integrity of the manuscript in accordance with ICMJE criteria. The article is original, has not already been published in a journal, and is not currently under consideration by another journal, We agree to the terms of the BioMed Central Copyright and License Agreement, and, where applicable, Open Data policy. Authors contributions:

Acknowledgements: No acknowledgements are applicable.

\section{FOOTNOTES}

${ }^{a}$ Alfa Aesar, Ward hill, MA

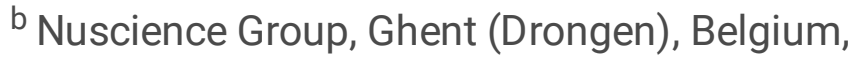

${ }^{\mathrm{c}}$ Kemin Industries, Des Moines, IA.

${ }^{d}$ PMI Nutritional Additives, Arden Hills, Minnesota, USA

${ }^{\text {e }}$ Framelco, Raamsdonksveer, Netherlands

${ }^{f}$ Nutreco, Amersfoort, Netherlands

${ }^{g}$ ADM, Chicago, Illinois

${ }^{\mathrm{h}}$ Cargill, Minneapolis, MN 
iSAS, version 9.4, SAS Institute Inc, Cary, NC.

\section{References}

1. Johny AK, Baskaran SA. Charles AS, et al. Prophylactic supplementation of caprylic acid in feed reduces Salmonella enteritidis colonization in commercial broiler chicks. J Food Prot. 2009; 72:722727.

2. Kim SA and Rhee MS. Marked synergistic bactericidal effects and mode of action of medium chain fatty acids in combination with organic acids in Escherichia coli 0157:H7. Appl Environ Microbiol. 2013;79:6552-6560.

3. Cochrane, R.A., Huss AR, Aldrich GC, Stark CR, and Jones CK. Evaluating chemical mitigation of Salmonella Typhimurium in animal feed ingredients. J Food Prot. 2016:79(4):672-676.

4. Cochrane RA, Dritz SS, Woodworth JC, et al. Assessing the effects of medium chain fatty acids and fat sources on PEDV RNA Stability and Infectivity. J Anim Sci. 2017;95 (E1) 196.

5. Cochrane RA, Saesukjaroenphon M, Dritz SS, et al. Evaluating the inclusion level of medium chain fatty acids to reduce the risk of PEDV in feed and spray-dried animal plasma. J Anim Sci. 2016;99(E2)107.

6. Cochrane RA, Dritz SS, Woodworth JC, et al. Evaluating chemical mitigation of PEDv in swine feed and ingredients. J Anim Sci. 2015;92(E2)090.

7. Dee S, Neill C, Clement T, et al. Modeling the transboundary risk of feed ingredients. contaminated with porcine epidemic diarrhea virus. BMC Vet Res. 2016;12:51-63.

8. Clinical and Laboratory Standards Institute (CLSI). Performance standards for antimicrobial disk and dilution susceptibility tests for bacteria isolated from animals. Approved standard, 4th ed. 2013. Document VET01-A4. CLSI, Wayne, PA.

9. Sukhija P.S., and Palmquest D.L. Rapid method for determination of total fatty acid content and composition of feedstuffs and feces. J Agric Food Chem. 1988;36:1202-1206.

10. Zentek J, Buchheit-Renko S, Ferrara F , et al. Nutritional and physiological role of medium-chain triglycerides and medium-chain fatty acids in piglets. Anim Health Res Rev. 2011;12(1):83-93

11. Batovska DI, Todorova IT, Tsvetkova IV, et al. Antibacterial study of the medium chain fatty acids and their 1-monoglycerides: Individual effect and synergistic relationships. Pol J Microbiol. 2009;58(1):43.47.

12. Skrivanova E, Marounek M, Benda V, et al. Susceptibility of Escherichia coli, Salmonella sp. and Clostridium perfringens to organic acids and monolaurin. Vet Med (Praha). 2006;51(3):81-88.

13. Hsiao CP, Siebert KJ. Modeling the inhibitory effects of organic acids on bacteria. Int J Food Microbiol. 1999;47:189-201.

14. Gottenbos B, Grijpma DW, van der Mei HC, et al. Antimicrobial effects of positively charged surfaces on adhering gram-positive and gram-negative bacteria. J Antimicrob Chemother. 2001;48(1):7-13. 


\section{Tables}


Table 1

Minimum inhibitory concentration of medium chain fatty acids in generic Escherichia coli, Enterotoxigenic Escherichia coli (ETEC), Salmonella enterica serotype Typhimurium, and Clostridium perfringens 1

\begin{tabular}{|c|c|c|c|}
\hline Item & MIC, \% & SEM & P-Value \\
\hline Campylobacter coli & & 0.047 & 0.0004 \\
\hline C6:0 & $0.50^{\mathrm{b}}$ & & \\
\hline C8:0 & $0.47^{b}$ & & \\
\hline C10:0 & $0.90^{a}$ & & \\
\hline 1:1:1 Blend & $0.43^{b}$ & & \\
\hline Clostridium perfringens & & 0.030 & $<0.0001$ \\
\hline C6:0 & $1.65^{a}$ & & \\
\hline C8:0 & $0.85^{\mathrm{b}}$ & & \\
\hline C10:0 & $0.70^{\mathrm{C}}$ & & \\
\hline $\mathrm{C} 12: 0$ & $0.25^{\mathrm{d}}$ & & \\
\hline Generic E. coli & & 0.014 & $<.0001$ \\
\hline C6:0 & $0.70^{a}$ & & \\
\hline C8:0 & $0.85^{\mathrm{b}}$ & & \\
\hline $\mathrm{C} 10: 0^{2}$ & $>1.00^{\mathrm{C}}$ & & \\
\hline 1:1:1 Blend & $0.60^{d}$ & & \\
\hline Enterotoxigenic E. coli & & 0.024 & $<.0001$ \\
\hline C6:0 & $0.53^{c}$ & & \\
\hline C8:0 & $0.67^{b}$ & & \\
\hline $\mathrm{C} 10: 0^{2}$ & $>1.00^{\mathrm{a}}$ & & \\
\hline 1:1:1 Blend ${ }^{2}$ & $>1.00^{\mathrm{a}}$ & & \\
\hline Salmonella Typhimurium & & 0.050 & $<.0001$ \\
\hline C6:0 & $0.40^{c}$ & & \\
\hline
\end{tabular}




\begin{tabular}{|c|c|c|c|}
\hline Item & MIC, \% & SEM & P-Value \\
\hline C8:0 & $0.50^{c b}$ & & \\
\hline $\mathrm{C} 10: 0^{2}$ & $>1.00^{\mathrm{a}}$ & & \\
\hline 1:1:1 Blend & $0.60^{b}$ & & \\
\hline \multicolumn{4}{|c|}{$\begin{array}{l}{ }^{1} \text { Minimum inhibitory concentration for } \mathrm{C6}: 0, \mathrm{C} 8: 0, \mathrm{C} 10: 0 \text {, and a } 1: 1: 1 \text { blend of } \mathrm{C6}: 0, \mathrm{C} 8: 0 \text {, and } \mathrm{C} 10: 0 \\
\text { were tested in E. coli, ETEC, S. Typhimurium, and C. coli using a } 96 \text { well microtiter plate with a } \\
\text { concentration of } 10^{5} \mathrm{CFU} / \mathrm{ml} \text { for each bacterial strain. For } \mathrm{C} \text {. perfringens, the compounds tested were } \\
\mathrm{C} 6: 0, \mathrm{C} 8: 0, \mathrm{C} 10: 0 \text {, and C12:0 utilizing a } 96 \text { well microtiter plate with a concentration of } 0.5 \text { McFarland } \\
\text { Standards for each well. Each value is represented by an } \mathrm{N}=3 \text {. } \\
{ }^{2} \text { Minimum inhibitory concentration was above the tested detection limit and therefore the next logical } \\
\text { inclusion level (increase in } 0.1 \% \text { inclusion) was utilized for the statistical analysis. } \\
\text { abcd Means within a bacterial species lacking a common superscript differ }(\mathrm{P}<0.05) \text {. }\end{array}$} \\
\hline
\end{tabular}


Table 2

Medium chain fatty acid profiles for the tested products $(\mathrm{mg} / \mathrm{g})$.

\begin{tabular}{|c|c|c|c|c|c|}
\hline Item & Total analyzed fatty acids & C6:0 & $\mathrm{C} 8: 0$ & C10:0 & C12:0 \\
\hline Product $A^{1}$ & 294.58 & 29.53 & 123.20 & 101.43 & 40.23 \\
\hline Product $\mathrm{B}^{2}$ & 1092.66 & 43.12 & 610.28 & 436.50 & 2.15 \\
\hline Product $\mathrm{C}^{1}$ & 123.07 & 12.35 & 51.42 & 42.28 & 16.85 \\
\hline Product $\mathrm{D}^{3}$ & 303.36 & 8.43 & 103.64 & 88.92 & 86.81 \\
\hline Product $\mathrm{E}^{3}$ & 369.33 & 9.02 & 123.38 & 105.61 & 111.06 \\
\hline Product $\mathrm{F}^{3}$ & 603.77 & 27.37 & 248.7 & 206.41 & 120.18 \\
\hline Product $\mathrm{G}^{3}$ & 494.34 & 0.98 & 227.13 & 188.00 & 74.50 \\
\hline Product $\mathrm{H}^{4}$ & 362.92 & 0.09 & 1.32 & 1.16 & 359.47 \\
\hline Product I 5 & 349.54 & 2.19 & 159.32 & 131.10 & 56.71 \\
\hline Product $\mathrm{J}^{5}$ & 101.32 & 0.00 & 41.42 & 34.03 & 25.70 \\
\hline Product $\mathrm{K}^{5}$ & 402.37 & 0.20 & 128.21 & 99.30 & 122.71 \\
\hline Product $L^{7}$ & 983.16 & 0.02 & 0.02 & 0.04 & 0.19 \\
\hline Product $\mathrm{M}^{7}$ & 520.80 & 3.78 & 40.87 & 31.21 & 227.83 \\
\hline Product $\mathrm{N}^{5}$ & 158.76 & 1.8 & 69.72 & 57.91 & 19.36 \\
\hline Product $\mathrm{O}^{5}$ & 145.57 & 1.74 & 68.08 & 56.43 & 18.56 \\
\hline Product $\mathrm{P}^{5}$ & 317.48 & 4.78 & 151.41 & 129.46 & 31.33 \\
\hline Product $Q^{5}$ & 2.78 & 0.00 & 0.02 & 2.60 & 0.00 \\
\hline Product $\mathrm{R}^{5}$ & 314.01 & 0.69 & 101.44 & 83.01 & 90.15 \\
\hline Coconut Oil ${ }^{6}$ & 894.09 & 6.82 & 72.07 & 53.74 & 409.62 \\
\hline Palm Oil ${ }^{6}$ & 894.34 & 0.00 & 0.51 & 0.22 & 2.35 \\
\hline Palm Kernel Oil 6 & 918.84 & 2.83 & 37.86 & 33.21 & 418.05 \\
\hline
\end{tabular}




\begin{tabular}{|c|c|c|c|c|}
\hline Total analyzed fatty acids & $\mathrm{C6:0}$ & $\mathrm{C} 8: 0$ & C10:0 & C12:0 \\
\hline \multicolumn{5}{|l|}{${ }^{1}$ Nuscience Group, Ghent (Drongen), Belgium } \\
\hline \multicolumn{5}{|l|}{2 Kemin Industries, Des Moines, IA. } \\
\hline \multicolumn{5}{|c|}{${ }^{3}$ PMI Nutritional Additives, Arden Hills, Minnesota, USA } \\
\hline \multicolumn{5}{|c|}{${ }^{4}$ Framelco, Raamsdonksveer, Netherlands } \\
\hline \multicolumn{5}{|l|}{${ }^{5}$ Nutreco, Amersfoort, Netherlands } \\
\hline \multicolumn{5}{|l|}{${ }^{6}$ ADM, Chicago, Illinois } \\
\hline${ }^{7}$ Cargill, Minneapolis, MN & & & & \\
\hline
\end{tabular}


Table 3

Minimum inhibitory concentration of commercially -based medium chain fatty acid based products in generic Escherichia coli, Enterotoxigenic Escherichia coli (ETEC), and Salmonella enterica serotype Typhimurium 1

\begin{tabular}{|c|c|c|c|}
\hline Item & MIC, \% & SEM & P-Value \\
\hline Campylobacter coli & & 0.629 & 0.0026 \\
\hline Product $A^{2}$ & $1.20^{\mathrm{cd}}$ & & \\
\hline Product $\mathrm{B}^{3}$ & $0.33^{d}$ & & \\
\hline Product $\mathrm{F}^{2}$ & $2.75^{\mathrm{bc}}$ & & \\
\hline Product $\mathrm{G}^{2}$ & $3.33^{\mathrm{ab}}$ & & \\
\hline Coconut oil ${ }^{4,5}$ & $>5.0^{\mathrm{a}}$ & & \\
\hline Generic E. coli & & 0.424 & $<.0001$ \\
\hline Product $A^{2}$ & $0.37^{c}$ & & \\
\hline Product $\mathrm{B}^{3}$ & $1.20^{\mathrm{c}}$ & & \\
\hline Product $\mathrm{F}^{2}$ & $3.33^{\mathrm{b}}$ & & \\
\hline Product $\mathrm{G}^{2}$ & $4.17^{\mathrm{ab}}$ & & \\
\hline Coconut oil ${ }^{4,5}$ & $>5.0^{\mathrm{a}}$ & & \\
\hline Enterotoxigenic E. coli & & 0.309 & $<.0001$ \\
\hline Product $A^{2}$ & $0.33^{c}$ & & \\
\hline Product $\mathrm{B}^{3}$ & $1.30^{c}$ & & \\
\hline Product $\mathrm{F}^{2}$ & $3.83^{b}$ & & \\
\hline Product $\mathrm{G}^{2}$ & $4.33^{\mathrm{ab}}$ & & \\
\hline Coconut oil ${ }^{4,5}$ & $>5.0^{\mathrm{a}}$ & & \\
\hline Salmonella Typhimurium & & 0.308 & $<.0001$ \\
\hline Product $A^{2}$ & $0.47^{c}$ & & \\
\hline Product $\mathrm{B}^{3}$ & $1.30^{c}$ & & \\
\hline Product $\mathrm{F}^{2}$ & $3.83^{b}$ & & \\
\hline
\end{tabular}




\begin{tabular}{|c|c|c|c|}
\hline Item & MIC, \% & SEM & P-Value \\
\hline Product $\mathrm{G}^{2}$ & $4.33^{\mathrm{ab}}$ & & \\
\hline Coconut oil ${ }^{4,5}$ & $>5.0^{a}$ & & \\
\hline \multicolumn{4}{|c|}{$\begin{array}{l}{ }^{1} \text { Minimum inhibitory concentration for products (Product A, B, F, G, and Coconut oil were tested in E. } \\
\text { coli, ETEC, S. Typhimurium, and C. coli using a } 96 \text { well microtiter plate with a concentration of } 10^{5} \\
\text { CFU/ml for each bacterial strain. Each value is represented by an } \mathrm{N}=3 \text {. } \\
{ }^{2} \text { Nuscience Group, Ghent (Drongen), Belgium } \\
{ }^{3} \text { Kemin Industries, Des Moines, IA. } \\
{ }^{4} \mathrm{ADM} \text {, Chicago, Illinois } \\
{ }^{5} \text { Minimum inhibitory concentration was above the tested detection limit and therefore the next logica } \\
\text { inclusion level (increase in } 0.1 \% \text { inclusion) was utilized for the statistical analysis. } \\
\text { abcd Means within a bacteria species lacking a common superscript differ }(\mathrm{P}<0.05) \text {. }\end{array}$} \\
\hline
\end{tabular}


Table 4

Effects of commercially-based products containing medium chain fatty acids on the growth of 106 $\mathrm{CFU} / \mathrm{g}$ feed Enterotoxigenic Escherichia coli (ETEC)1

\begin{tabular}{|c|c|c|c|c|}
\hline Item & Log CFU/g & SEM & Linear & Quadratic \\
\hline Product $A^{2}$ & & 0.011 & $<.0001$ & 0.9641 \\
\hline $0.00 \%$ & 5.44 & & & \\
\hline $0.25 \%$ & 5.37 & & & \\
\hline $0.50 \%$ & 5.24 & & & \\
\hline $1.00 \%$ & 5.15 & & & \\
\hline $2.00 \%$ & 4.81 & & & \\
\hline Product $\mathrm{B}^{3}$ & & 0.017 & $<.0001$ & $<.0001$ \\
\hline $0.00 \%$ & 5.44 & & & \\
\hline $0.50 \%$ & 5.19 & & & \\
\hline $1.00 \%$ & 5.14 & & & \\
\hline $2.00 \%$ & 4.71 & & & \\
\hline $4.00 \%$ & 3.49 & & & \\
\hline \multicolumn{5}{|c|}{$\begin{array}{l}1 \text { Product A and B were tested in a concentration of } 10^{6} \mathrm{CFU} / \mathrm{g} \text { of feed ETEC in a complete swine diet } \\
\text { in order to determine the growth of that bacteria using MacConkey agar containing nalidixic acid for } \\
\text { bacterial enumeration } \\
{ }^{2} \text { Nuscience Group, Ghent (Drongen), Belgium } \\
{ }^{3} \text { Kemin Industries. Des Moines, IA. }\end{array}$} \\
\hline
\end{tabular}


Table 5

Effects of commercially-based products containing medium chain fatty acids on the growth of 102 $\mathrm{CFU} / \mathrm{g}$ feed Enterotoxigenic Escherichia coli (ETEC)1

\begin{tabular}{|c|c|c|c|c|}
\hline Item & Log CFU/g & SEM & Linear & Quadratic \\
\hline Product $A^{2}$ & & 0.007 & 0.0060 & 0.1180 \\
\hline $0.00 \%$ & 2.95 & & & \\
\hline $0.25 \%$ & 2.93 & & & \\
\hline $0.50 \%$ & 2.93 & & & \\
\hline $1.00 \%$ & 2.95 & & & \\
\hline $2.00 \%$ & 2.91 & & & \\
\hline Product $\mathrm{B}^{3}$ & & 0.012 & 0.1041 & 0.1579 \\
\hline $0.00 \%$ & 2.95 & & & \\
\hline $0.50 \%$ & 2.90 & & & \\
\hline $1.00 \%$ & 2.93 & & & \\
\hline $2.00 \%$ & 2.91 & & & \\
\hline $4.00 \%$ & 2.91 & & & \\
\hline \multicolumn{5}{|c|}{$\begin{array}{l}1 \text { Product A and B were tested in a concentration of } 10^{2} \mathrm{CFU} / \mathrm{g} \text { of feed ETEC in a complete swine diet } \\
\text { in order to determine the growth of that bacteria using MacConkey agar containing nalidixic acid for } \\
\text { bacterial enumeration } \\
2 \text { Nuscience Group, Ghent (Drongen), Belgium } \\
{ }^{3} \text { Kemin Industries. Des Moines, IA. }\end{array}$} \\
\hline
\end{tabular}

